\title{
Avaliação da permeabilidade de luvas de látex utilizadas em laboratório para a manipulação de nanopartículas poliméricas
}

\author{
Laís Schmidt \\ Cristiane Bastos de Mattos ${ }^{1}$ \\ Vanusca Dalosto Jahno ${ }^{1}$ \\ Carlos Leonardo Pandolfo Carone ${ }^{1}$ \\ Luis Fernando Hoffmann ${ }^{1}$ \\ Cláudia Trindade Oliveira ${ }^{l}$ \\ Sandra Raquel Kunst ${ }^{2}$ \\ Jane Zoppas Ferreira ${ }^{2}$ \\ Fernando Dal Pont Morisso ${ }^{1 *}$ (1)
}

\section{Resumo}

Este trabalho mostra uma avaliação da permeabilidade das luvas de látex, utilizadas na preparação/manipulação de rotina em um laboratório que desenvolve materiais manométricos. As luvas foram utilizadas como barreira física para partículas preparadas com poli(E-caprolactona). As partículas foram analisadas por meio de potencial zeta, tamanho, $\mathrm{pH}$, índice de refração e condutividade. As luvas de látex foram utilizadas como barreira física nos ensaios em células de difusão de Franz, em 3, 5 e 8h, e a turbidez do fluido receptor. As luvas também foram analisadas por espectrofotometria no infravermelho (FTIR) e microscopia eletrônica de varredura (MEV). As partículas preparadas para o ensaio de permeação mantiveram-se estáveis durante, por dois meses e os valores de turbidez foram de aproximadamente 1,3 NTU para diluições de 1:5 do fluido receptor, após 8 horas de ensaio. O FTIR não evidenciou alteração química na estrutura da luva, mas observa-se, ao MEV, alteração morfológica no material constituinte. As luvas testadas são permeáveis às nanopartículas poliméricas a que foram submetidas.

Palavras-chave: Luvas; Permeação; Célula de difusão de franz; Nanopartículas.

\section{Evaluation of the permeability of latex gloves used in a laboratory for the handling of polymeric nanoparticles}

\begin{abstract}
This work shows an evaluation of the permeability of latex gloves, used in routine preparation/manipulation in a laboratory that develops manometric materials. The gloves were used as a physical barrier for particles prepared with poly ( $\varepsilon$-caprolactone). The particles were analyzed by means of zeta potential, size, $\mathrm{pH}$, refractive index and conductivity. Latex gloves were used as the physical barrier in the assays in Franz diffusion cells at 3,5 and $8 \mathrm{~h}$, and the turbidity of the recipient fluid. The gloves were also analyzed by infrared spectrophotometry (FTIR) and scanning electron microscopy (SEM). The particles prepared for the permeation assay were held stable for two months and the turbidity values were approximately 1.3 NTU for 1: 5 dilutions of the receiving fluid after 8 hours of assay. The FTIR showed no chemical alteration in the glove structure, but it is observed, to the SEM, morphological alteration in the constituent material. The gloves tested are permeable to the polymer nanoparticles to which they were subjected.
\end{abstract}

Keywords: Gloves; Permeation; Franz diffusion cell; Nanoparticles.

${ }^{I}$ Instituo de Ciências Criativas e Tecnológicas - ICCT, Universidade Feevale, Novo Hamburgo, RS, Brasil.

${ }^{2}$ Laboratório de Corrosão - LACOR, Universidade Federal do Rio Grande do Sul-UFRGS, Porto Alegre, RS, Brasil.

*Autor correspondente: morisso@feevale.br 


\section{Introdução}

A crescente expansão das nanotecnologias permitiu que, em 2015, pelo menos dois milhões de pessoas trabalhassem em diferentes campos da ciência e tecnologia no mundo. Esse contingente atuou no desenvolvimento de novos produtos como medicamentos, tecidos sintéticos, dispositivos eletrônicos e terapias medicinais, dentre outros segmentos [1]. Porém, a manipulação dessas estruturas com dimensões nanométricas exige uma nova avaliação do ponto de vista da saúde e segurança dos indivíduos, além de informações mais detalhadas referentes aos riscos toxicológicos dos diferentes materiais nestas dimensões [2]. Neste contexto, a nanotecnologia compreende diversos materiais e dispositivos que possuem pelo menos uma dimensão nanométrica na casa do bilionésimo de metro ( $1 \times 10^{-9}$ metros). Isso significa que podem ser menores que diversas moléculas biológicas [3].

Como uma fração do universo nanotecnológico, nanopartículas podem penetrar no corpo humano de diferentes formas, mas a inalação é a rota de exposição mais comum no ambiente de trabalho. Por esta via, partículas nanométricas aderem-se aos alvéolos, prejudicando atividades vitais como a troca gasosa [4]. Nanopartículas também podem penetrar na pele, atingindo a corrente sanguínea e distribuindo-se por todo corpo, incluindo o cérebro [5].

O potencial risco toxicológico de nanopartículas ainda não está bem elucidado, porém já foram observados danos no organismo relacionados ao estresse oxidativo. Ações neste sentido podem afetar atividades biológicas e induzir resposta inflamatória generalizada. Os principais fatores que contribuem para a toxicidade das nanopartículas em geral estão relacionados com seu diâmetro, comprimento e o baixo clearance, ou seja, a capacidade de filtração glomerular que pode causar deficiência renal [6].

Com a observação desses eventos, a French Agency for Environmental and Occupational Health Safety (Afsset) emitiu um parecer orientando os pesquisadores que as nanopartículas devem ser consideradas como nível de perigo desconhecido e devem ser manipuladas com a mesma cautela de materiais perigosos [2]. Da mesma forma, a Food and Drug Administration (FDA) está tomando decisões regulatórias que atingem desde produtos cosméticos e quimioterápicos até embalagens de alimentos. Segundo a agência, produtos nanotecnológicos têm atributos que diferem de produtos fabricados de forma convencional e, portanto, necessitam de novas avaliações de segurança e eficácia [7].

Assim, uma das principais recomendações para um sistema eficiente de regulação racional de produtos nanoparticulados é a existência de uma equipe multidisciplinar envolvendo especialistas na área da farmacologia, toxicologia, química, engenharia química, etc. Essa equipe regulatória composta, assim, por pessoal competente para a avaliação de um novo paradigma material, deve realizar suas atividades com base em dados experimentais e, ao mesmo tempo, auxiliar no desenvolvimento de ferramentas e técnicas para manipulação em geral de materiais nanométricos, levando em consideração a qualidade, segurança e eficácia de tais produtos $[8,9]$.

A American Industrial Hygiene Association (AIHA) indica que para a manipulação de materiais nanoparticulados devem ser selecionadas luvas de acordo com sua eficácia frente a essas estruturas, considerando requisitos como calor e ação mecânica. Assim, a espessura da luva contribui para a segurança do manipulador, sendo a penetração de partículas mais provável após deformações mecânicas. Por esse fato, é aconselhada a troca regular, além do uso de duas camadas de luvas, quando possível. Além disso, esse equipamento individual de proteção (EPI) não deve ser considerado como principal via de proteção, uma vez que não se conhece a eficácia de tais materiais para essa dimensão de partícula [10].

Nessa perspectiva alguns autores vêm realizando ensaios de avaliação da eficiência de EPI's como barreira física a fim de minimizar a possível toxicidade de nanopartículas. Esses estudos mostraram que as estruturas analisadas possuem capacidade de permeação de acordo com a composição da luva e das partículas avaliadas $[2,11,12]$. Dessa forma, este estudo preliminar teve como objetivo avaliar a permeabilidade de luvas de látex utilizadas na preparação/manipulação de rotina em um laboratório que desenvolve materiais nanométricos, a fim de verificar se o EPI funciona como barreira física para esse tipo de partícula.

\section{Metodologia}

O material utilizado foram luvas de látex e não passaram por tratamento anterior à sua utilização como corpo de prova. Os reagentes utilizados nos experimentos foram adquiridos em grau para análise e não receberam tratamento específico antes de sua utilização. Todos os procedimentos experimentais e analíticos foram realizados em triplicata.

\subsection{Preparação e caracterização das nanopartículas}

As nanopartículas poliméricas de poli( $\varepsilon$-caprolactona) $(\mathrm{PCL}$, Massa molar $=45.000 \mathrm{~g} / \mathrm{mol}$ ) foram preparadas segundo método de nanoprecipitação e não contiveram núcleo oleoso, ou seja, eram esferas. Todas as formulações foram preparadas em triplicata em condições de temperatura de $22,1 \pm 0,6^{\circ} \mathrm{C}$ e de umidade de $58 \pm 6 \%$.

Inicialmente, preparou-se a fase orgânica, composta por $5 \mathrm{mg}$ de Span 80 (tensoativo lipofílico), $5 \mathrm{mg}$ de policaprolactona (PCL) e $20 \mathrm{~mL}$ de acetona (solvente orgânico). A PCL foi adicionada à acetona e o sistema foi mantido sob agitação magnética constante a $40^{\circ} \mathrm{C}$ durante 1h. Quando essa solução apresentou característica límpida e homogênea, adicionou-se o Span. A agitação permaneceu por mais 30 minutos.

A fase aquosa composta por $73 \mathrm{~mL}$ de água (solvente) e $2 \mathrm{mg}$ de Tween 80 (tensoativo hidrofílico) foi mantida sob agitação magnética a $30^{\circ} \mathrm{C}$, durante 30 minutos a fim 
de que todas as fases estivessem na mesma temperatura quando de sua mistura.

O conteúdo da fase orgânica foi transferido para o béquer contendo a fase aquosa, a uma taxa de adição de $6 \mathrm{~mL} / \mathrm{min}$. Manteve-se a agitação magnética e temperatura de $30^{\circ} \mathrm{C}$ até completa evaporação do solvente.

Em seguida, a solução de nanopartículas poliméricas foi centrifugada a $3500 \mathrm{rpm}$, durante 30 minutos, para a retirada de resíduos poliméricos que não formaram partículas e que se apresenta, na forma de aglomerados de dimensões maiores que a nanométrica. Posteriormente, utilizou-se evaporador rotativo para eliminação de resíduos do solvente orgânico, a fim de não interferir na permeação. O processo de evaporação durou uma hora e a dispersão de nanopartículas resultante foi acondicionada em frasco de vidro âmbar.

As formulações foram caracterizadas quanto ao tamanho de partícula, índice de polidispersão e potencial zeta, utilizando o equipamento NanoBrook 90Plus Pals (Brookhaven Instruments Corporation). Para a realização dessas análises, as amostras foram diluídas a 1:100 com solução de $\mathrm{KCl} 10 \mathrm{mM}$. A determinação do tamanho de partícula foi realizada por meio da técnica de espalhamento dinâmico de luz (DLS) em ângulo de $90^{\circ}$ e o cálculo do potencial zeta foi realizado a partir da mobilidade eletroforética, avaliada por análise de fase do espalhamento de luz (PALS).

A análise de $\mathrm{pH}$ foi realizada por meio de leitura direta em potenciômetro previamente calibrado. As análises de índice de refração foram realizadas em refratômetro $\mathrm{ABBE}$, marca Quimis, modelo ABBE Refractometer Q767BD. Já a condutividade das amostras foi medida em condutivímetro DIGIMED DM-32.

Para análises morfológicas, as amostras foram metalizadas em equipamento Denton Vaccum (Desk V) para posterior verificação em microscópio eletrônico de varredura (MEV) JEOL JSM-6510LV.

A análise de turbidez foi realizada em turbidímetro Merck modelo Turbiquant IR3000 com faixa de leitura entre 0 - 10.000 NTU. Em função da capacidade do compartimento receptor, as amostras de $5 \mathrm{~mL}$ foram avolumadas em um balão de 25 mL com solução tampão de $\mathrm{pH}$ 7,4 devidamente filtrado.

As análises de infravermelho (FT-IR) foram realizadas em espectrofotômetro Perkin Elmer Spectrum Two, com acessório de refletância universal atenuada (UATR).

As células de Franz foram confeccionadas sob medida, com volume de $10 \mathrm{~mL}$ no compartimento receptor.

\subsection{Permeação utilizando a célula de difusao de Franz}

Para os ensaios de permeação, foram utilizadas luvas novas de látex, retiradas aleatoriamente da mesma caixa. De cada luva foi retirada uma amostra que foi utilizada como membrana de interface entre o compartimento receptor e o doador na célula de difusão de Franz. A dispersão de nanopartículas foi adicionada ao compartimento superior/ doador, em um volume de $1 \mathrm{~mL}$.

O compartimento inferior/receptor foi totalmente preenchido com solução tampão fosfato de $\mathrm{pH} 7,4$ filtrado a vácuo com filtro hidrofílico de porosidade $0,22 \mu \mathrm{m}$, marca Nova Analítica.

As células ficaram sob agitação magnética constante a $2000 \mathrm{rpm}$, em temperatura de $25^{\circ} \mathrm{C}$. O sistema foi mantido durante três períodos distintos de 3,5 e $8 \mathrm{~h}$, sendo que, no final de cada tempo, as amostras de permeado foram coletadas integralmente para análises.

As luvas que ficaram entre os compartimentos doador e receptor, após período de permeação, foram limpas com água ultrapura e colocadas em placa de Petry no dessecador para secarem naturalmente.

\subsection{Análise estatística}

Todos os dados obtidos foram compilados em planilha do Microsoft Excel®. Nessa planilha foram calculados média, desvio padrão e coeficiente de variação percentual, assumindo como limite de variação aceitável um fator de 20\%. Quando necessário, foi aplicado o método Anova de fator único com nível de significância $P<0,05$ para aprovação da hipótese.

\section{Resultados e discussão}

As dispersões de nanopartículas foram preparadas em triplicata. As amostras foram caracterizadas quanto ao tamanho de partícula, índice de polidispersão, potencial zeta, pH, índice de refração, turbidez e condutividade (Tabela 1). Os resultados foram expressos como média \pm DP.

O tamanho de partícula das amostras 1 a 3 foi submetido à análise estatística Anova e o teste demonstrou homogeneidade entre as amostras, indicando que o método de preparação pode ser considerado reprodutível. Os índices de polidispersão menores que 0,3 indicam distribuição

Tabela 1. Parâmetros de caracterização das partículas utilizadas nos ensaios de permeação

\begin{tabular}{ccrr}
\hline Parâmetros de caracterização & Amostra 1 & Amostra 2 & Amostra 3 \\
\hline Tamanho de partícula $(\mathrm{nm})$ & $202,28 \pm 7,28$ & $205,13 \pm 1,43$ & $188,31 \pm 2,76$ \\
Índice de polidispersão & $0,10 \pm 0,01$ & $0,09 \pm 0,009$ & $0,11 \pm 0,02$ \\
Potencial Zeta $(\mathrm{mV})$ & $-24,03 \pm 0,70$ & $-28,53 \pm 2,17$ & $-31,94 \pm 2,22$ \\
pH & $5,91 \pm 0,54$ & $6,34 \pm 0,75$ & $7,12 \pm 0,33$ \\
Condutivímetro $(\mu \mathrm{S})$ & $6,703 \pm 0,16$ & $5,536 \pm 0,07$ & $5,948 \pm 0,10$ \\
Índice de refração & $1,3352 \pm 0,0002$ & $1,3354 \pm 0,0004$ & $1,3354 \pm 0,0001$ \\
Turbidez (NTU) & $125,12 \pm 0,34$ & $117,98 \pm 0,12$ & $122,39 \pm 0,35$ \\
\hline
\end{tabular}


uniforme no tamanho das partículas [13,14]. Sendo assim, é possível reconhecer a adequação do método de preparação das partículas utilizadas neste estudo.

Da mesma forma, potenciais zeta em torno de $30 \mathrm{mV}$, em módulo, sugerem sistemas mais estáveis [13,14]. Assim, nas amostras analisadas, este parâmetro está próximo ao valor de referência.

No entanto, ao avaliar a estabilidade após dois meses da preparação, as três amostras de dispersão das partículas não apresentaram alterações significativas. O tamanho de partícula encontrou-se entre 192 e $211 \mathrm{~nm}$, bem como ausência de aglomerados ou separação de fases de qualquer natureza. Da mesma forma, a turbidez não sofreu alteração significativa, decorrido este período. O potencial zeta, por outro lado, aumentou para a faixa de $-15 \mathrm{a}-19 \mathrm{mV}$, demostrando que a dispersão se tornou menos estável ao longo do tempo. O $\mathrm{pH}$, o índice de refração e a condutividade apresentaram-se estatisticamente semelhantes entre as amostras, corroborando a sugestão de que o método de preparação é adequado à obtenção das partículas.

\subsection{Caracterização das luvas}

As luvas utilizadas nos experimentos de permeação foram avaliadas morfologicamente utilizando microscopia eletrônica de varredura e espectroscopia de infravermelho.

A Figura 1 mostra na linha A fotomicrografias de superfície e de corte transversal das luvas de látex antes do teste de permeabilidade. A partir das imagens foi possível observar uma superfície rugosa e presença de poros no corte transversal, indicados por setas brancas. As micrografias obtidas para este conjunto de luvas são compatíveis com outras micrografias apresentadas na literatura $[2,12,15]$.

A Figura 1, na linha B, mostra as fotomicrografias da superfície e corte transversal das luvas, após 8 horas de desenvolvimento do teste de permeação.

Comparando as imagens das linhas A e B é possível sugerir que o teste de permeação parece alterar a estrutura física da luva. Ao comparar os cortes transversais, observa-se poros aparentemente maiores após 8 horas de permeação. Da mesma forma, pode-se perceber que a superfície da amostra submetida a 8 horas de permeação apresenta-se mais homogêneas do que antes do teste. O comportamento é semelhante para as amostras com 3 e 5 horas de desenvolvimento do teste de permeação (dados não mostrados). Não foi observada diferença significativa entre os lados das luvas.

Esses resultados encontram correspondência no trabalho de Dolez et al. [2], que realizaram uma pesquisa de investigação preliminar utilizando microscópio eletrônico de varredura que permitiu observar a presença de nanopartículas de sílica com cerca de $40-50 \mathrm{~nm}$ depositadas em fissuras formadas na superfície de luvas nitrílicas após manuseio de uma solução coloidal em isopropanol. Como resultado dos ensaios, os autores recomendam a troca frequente
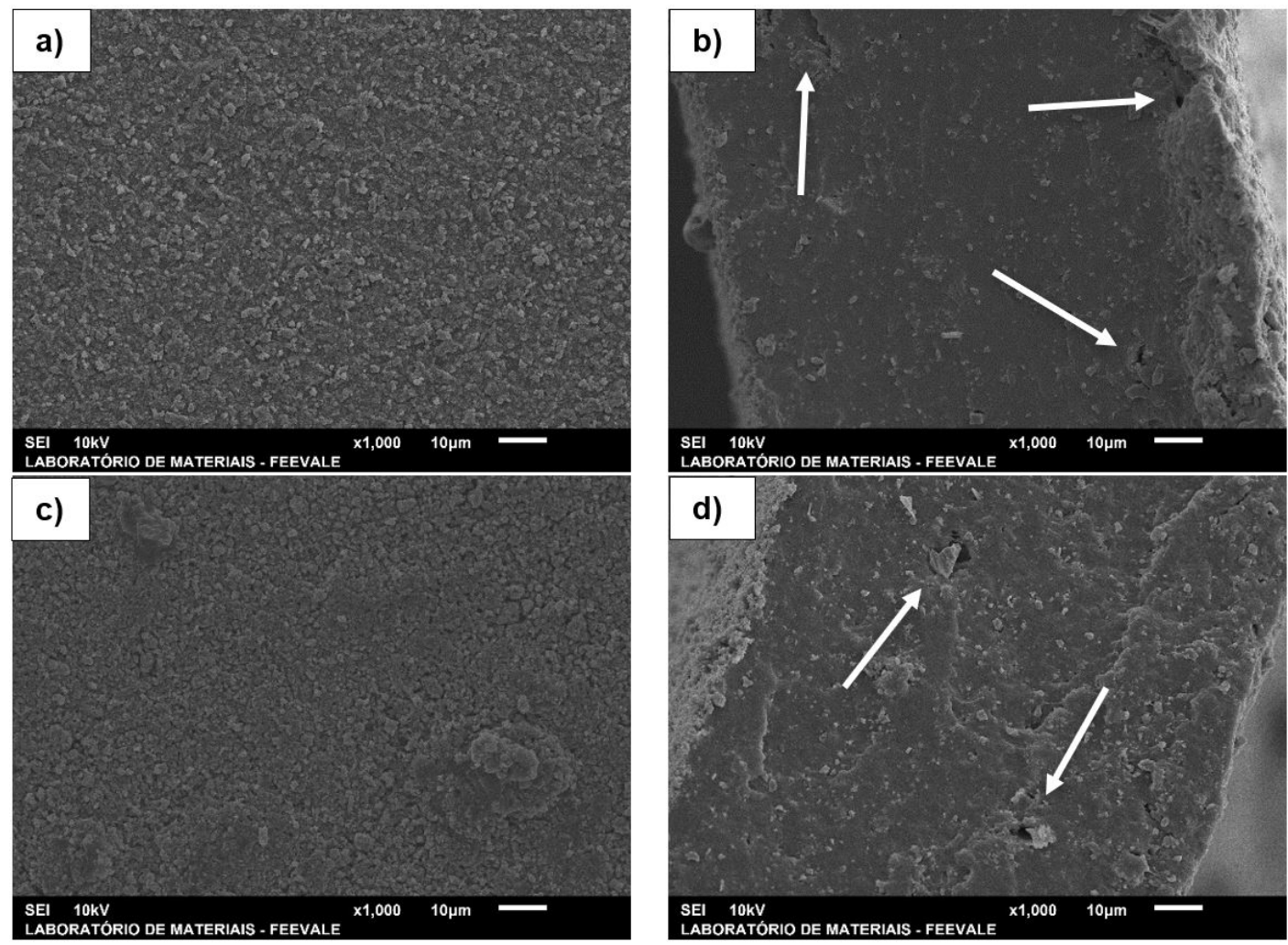

Figura 1. Micrografias das luvas de látex utilizadas nos testes de permeação. (a) antes do teste de permeação vista superficial; (b) antes do teste de permeação corte transversal; (c) depois de 8 horas de permeação vista superficial; e (d) depois de 8 horas de permeação corte transversal. 
das luvas, principalmente quando se estiver manipulando soluções coloidais nanoparticuladas. Em outra oportunidade, Dolez et al. [15] evidenciaram mudança significativa na superfície de luvas nitrílicas após 7 horas de deformação. No trabalho desses autores, pode-se perceber que o diâmetro e a profundidade dos poros aumentam, bem como a existência de aglomerações de nanopartículas nessas imperfeições, o que pode indicar uma fragilização da membrana.

Da mesma forma, Vinches et al. [11] observou que as luvas nitrílicas são permeáveis após $5 \mathrm{~h}$ de deformação biaxiais, pois permitiram a passagem de nanopartículas de dióxido de titânio.

Também, Vinches et al. [11] avaliaram a permeação de nanopartículas de dióxido de titânio $\left(\mathrm{TiO}_{2}\right)$ em luvas nitrílicas e butílicas. Esses autores verificaram a variação das características das luvas após determinado tempo com repetidas deformações, simulando o uso durante a manipulação. O estudo constatou que as luvas butílicas não são permeáveis ao pó de dióxido de titânio, mesmo com a ação dos processos de simulação de uso. Por outro lado, as luvas nitrílicas, ao sofrerem deformações, apresentaram mudança significativa no diâmetro e profundidade dos poros e, dessa forma, permitiram a permeação tanto de partículas de dióxido de titânio em pó, quanto em preparações coloidais.

Além disso, embora testando a permeação de óleo mineral e não de partículas nanométricas, é possível mencionar o trabalho de Irzmańska e Dyńska-Kukulska [12], pois este apresenta-se preocupado com o aspecto da proteção. O estudo apresenta uma breve revisão bibliográfica juntamente com resultados experimentais sobre a permeação do óleo em luvas de proteção contra agentes químicos.

Considerando os resultados de espectrofotometria no infravermelho, a Figura 2 apresenta sobreposição dos espectros de Infravermelho da amostra de luva látex nova e após 8 horas de permeação.

É possível notar que não houve diferença significativa entre os espectros, o que concorda com a manutenção das estruturas química das luvas. $\mathrm{O}$ assinalamento das bandas nos espectros de infravermelho está de acordo com a literatura $[16,17]$.

\subsection{Permeação das nanopartículas}

Segundo a literatura, a luva de látex não oferece proteção quando em contato com óleos, graxas e solventes orgânicos
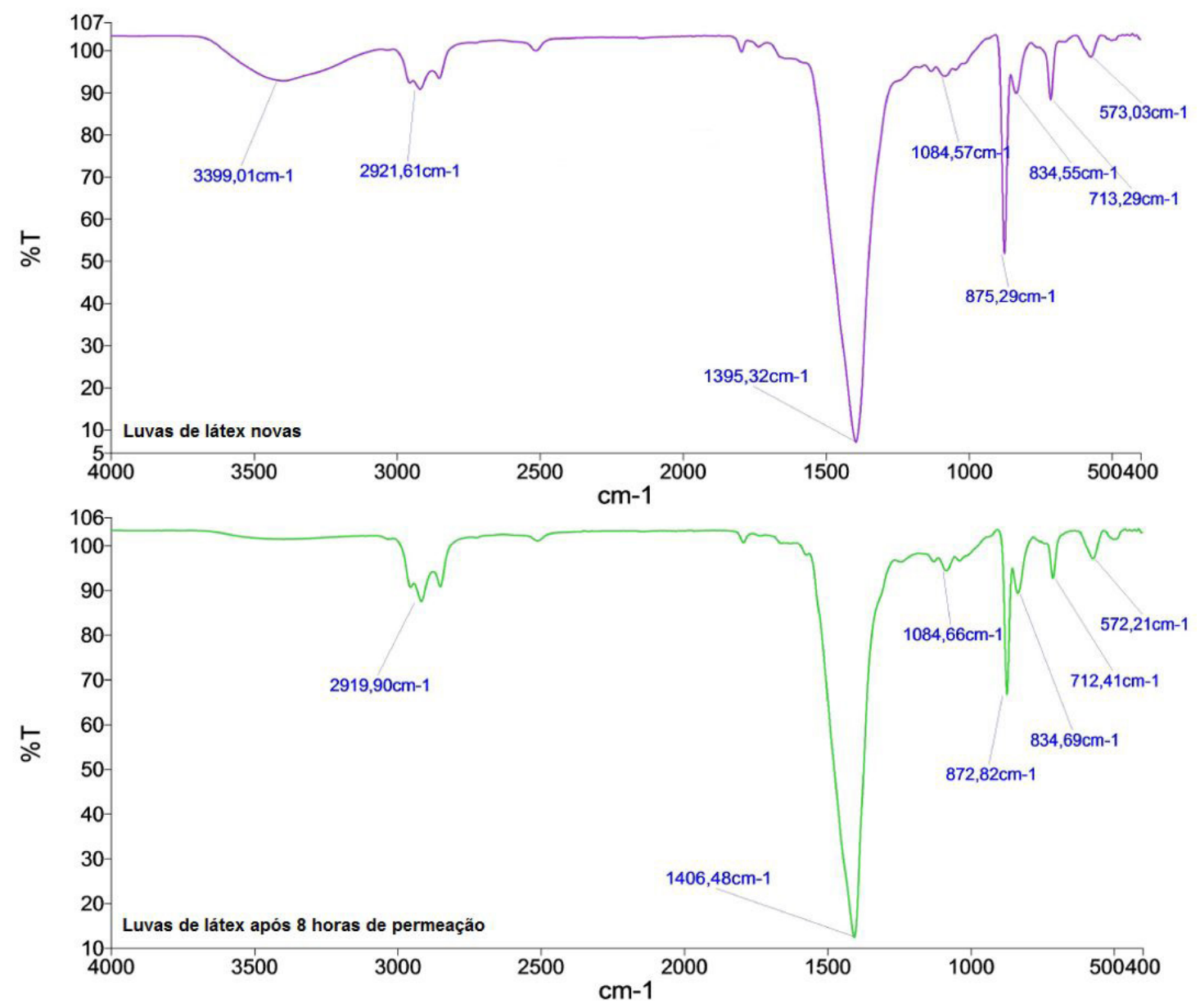

Figura 2. Espectros de Infravermelho da amostra de luva de látex nova e após 8 horas de permeação. 


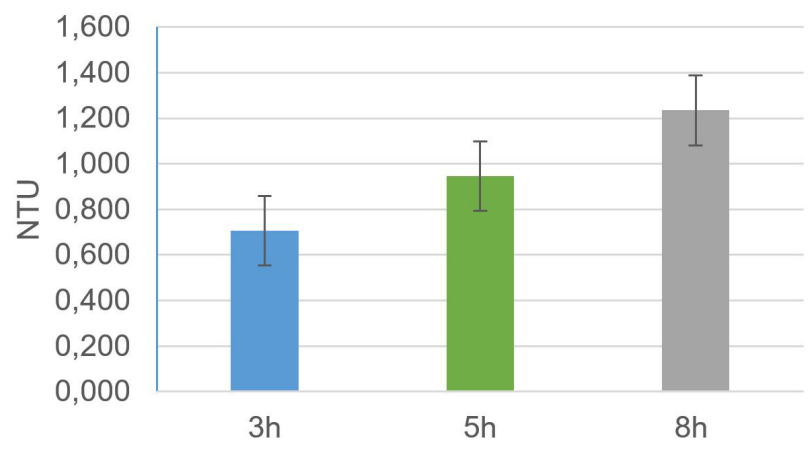

Figura 3. Turbidez dos permeados de acordo com o período de permeação.

$[18,19]$. Levando em consideração essas informações, o teor residual do solvente da fase orgânica, acetona, da preparação das dispersões nanométricas foi retirado com auxílio de evaporação rotativa. Para avaliar se o solvente da fase orgânica foi retirado com o processo de evaporação, foi medido o índice de refração da dispersão, que se mostrou muito semelhante ao da água como pode ser observado na Tabela 1.

$\mathrm{O}$ índice de refração das dispersões utilizadas na permeação também não foi alterado com o passar do tempo, mesmo após dois meses da preparação das dispersões. Esse aspecto, inclusive, denota que a permeação das dispersões não causa nenhum efeito de dissolução de componentes das luvas, pois o índice de refração pode ser utilizado para caracterizar e descrever a pureza de líquidos [20,21].

A solução de tampão fosfato $\mathrm{pH} 7,4$ utilizada como líquido receptor nos ensaios de permeação apresentou turbidez residual com leituras muito baixas e instáveis para registro. No entanto, o primeiro indício da presença de nanopartículas em uma dispersão pode ser a expressão do efeito Tyndall, que corresponde ao espalhamento de luz proporcionado por um sistema disperso quando irradiado por um feixe de luz [22,23]. Este efeito não foi verificado na solução tampão utilizada como receptor dos permeados, quando analisada após filtração, sugerindo que não haviam partículas relevantes dispersas no tampão. Após a realização dos ensaios de permeação, o fluido receptor foi, novamente, avaliado quanto a sua turbidez.

Uma vez constatada a presença de partículas dispersas no permeado, utilizou-se a turbidimetria para a avaliação quantitativa das nanopartículas presentes nos permeados. Os resultados obtidos nesta análise são apresentados na Figura 3 como média \pm DP.

A partir do Figura 3, é possível observar a evolução da permeação das luvas de látex em função do período de avaliação. É importante mencionar que alto desvio padrão das medidas foi atribuído à proximidade do limite inferior de detecção do equipamento, o que gerou certa instabilidade nas leituras.

A condutividade das amostras de permeado manteve-se em torno de 7,30 $\pm 0,05 \mathrm{mS}$, enquanto esse mesmo parâmetro na dispersão de nanopartículas utilizadas foi de $6,06 \pm 0,59 \mu \mathrm{S}$. Esse resultado pode ser interpretado como decorrente da presença dos eletrólitos da solução tampão.
Os resultados encontrados no estudo preliminar apresentam alinhamento com os resultados da literatura. Alguns autores $[11,15]$ observaram a permeação de nanopartículas, especialmente quando essas estiverem dispersas e quando a luva foi submetida a deformações mecânicas. Dessa forma, é importante refletir sobre os procedimentos dos trabalhadores e pesquisadores que manipulam diariamente materiais nanoparticulados. Esses indivíduos estão sendo expostos e não se conhece o real risco dessas partículas, por isso é recomendada a troca regular das luvas, bem como o uso de duas camadas dessas, quando possível.

Além disso, estudos relacionados com o risco ocupacional de nanopartículas sugerem o uso de partículas na forma de semissólidos, em substituição a forma de pó e spray, que são facilmente dispersas [10,24]. Da mesma forma, a absorção dérmica de materiais nanoparticulados ainda é pouco relatada, porém, sabe-se que partículas de diferentes características físico-químicas podem penetrar na pele íntegra, ficando depositadas na camada dérmica e epidérmica por até $24 \mathrm{~h}$ e partículas com até $40 \mathrm{~nm}$ penetram através da via folicular, atingindo, assim, camadas mais profundas [24,25].

\section{Conclusões}

Os resultados coletados com o desenvolvimento deste trabalho preliminar de avaliação da permeabilidade das luvas de látex frente a nanopartículas poliméricas, indicam possíveis permeações dos materiais nanoparticulados através das luvas, uma vez que as análises turbidimétricas demonstraram aumento da concentração com o passar do tempo ( 3,5 e $8 \mathrm{~h})$.

Da mesma forma, ao analisar microscopicamente as luvas após os testes de permeação, verificou-se que essas aparentemente apresentaram diferença em seus poros e superfície. Nessa perspectiva, é importante refletir sobre a eficiência dos equipamentos de proteção individual que são oferecidos aos manipuladores de nanomateriais, como óxidos e partículas poliméricas.

Sendo assim, é recomendada a troca de luvas regularmente, além da utilização de duas camadas desse material, já que partículas nanométricas estão cada vez mais presentes no cotidiano de pesquisadores e trabalhadores, não se conhecendo o seu real risco. Essas descobertas evidenciam a relevância e a importância de prosseguir a pesquisa neste campo.

\section{Agradecimentos}

Os autores agradecem a Secretaria de Desenvolvimento Econômico, Ciência e Tecnologia do Estado do Rio Grande do Sul (SDECT), bem como à CAPES, CNPq e ao Laboratório de Estudos Avançados em Materiais da Universidade Feevale. 


\section{Referências}

1 Silva GFBL, Silva LCL. Saúde e segurança ocupacional: reflexões sobre os riscos potenciais e o manuseio seguro dos nanomateriais. Vigilância Sanitária em Debate. 2013;1(1):43-52.

2 Dolez PI, Bodila N, Lara J, Truchon G. Personal protective equipment against nanoparticles. International Journal of Nanotechnology. 2010;7(1):99-117.

3 Oliveira OJ. Nanostructures. Cambridge: Elsevier; 2016. 261 p.

4 Santos PC. Nanopartículas: toxicidade biológica [trabalho de conclusão de curso]. João Pessoa: Curso de Farmácia, Universidade Federal da Paraíba; 2014.

5 Santos EP. Nanotecnologia: fundamentos, aplicações e oportunidades. Rio de Janeiro: Laboratório Galênico, Departamento de Medicamentos, Faculdade de Farmácia, Universidade Federal do Rio de Janeiro; 2009.

6 Moniz AMCPB. Exposição profisssional a nanopartículas na indústria farmacêutica: estudo exploratório [dissertação]. Lisboa: Mestrado em Segurança e Higiene no trabalho, Escola Superior de Tecnologia da Saúde de Lisboa; 2013.

7 U.S. Food and Drug Administration. FDA's approach to regulation of nanotechnology products. Washington: FDA; 2015 [acesso em 20 jun. 2017]. Disponível em: https://www.fda.gov/scienceresearch/specialtopics/nanotechnology/ ucm301114.htm

8 Bawa R, Melethil S, Simmons W, Harris D. Nanopharmaceuticals: patenting issues and FDA regulatory challenges. Chicago: American Bar Association; 2008.

9 Musazzi UM, Marini V, Casiraghi A, Minghetti P. Is the european regulatory framework sufficient to assure the safety of citizens using health products containing nanomaterials? Drug Discovery Today. 2017;22(6):870-882.

10 American Industrial Hygiene Association. Personal protective equipment for engineered nanoparticles workplace. Falls Church: AIHA; 2015 [acesso em 13 abr. 2017]. Disponível em: https://www.aiha.org/government-affairs/ documents/personal protective equipment for engineered nanoparticles_final.pdf

11 Vinches L, Testori N, Dolez P, Perron G, Wilkinson KJ, Hallé S. Experimental evaluation of the penetration of $\mathrm{TiO}_{2}$ nanoparticles through protective clothing and gloves under conditions simulating occupational use. Nanoscience Methods. 2013;2(1):1-15.

12 Irzmańska E, Dyńska-Kukulska K. Permeation of mineral oils through protective glove materials in view of literature data and authors' own studies. Reviews in Analytical Chemistry. 2012;31(2):113-122.

13 Kong M, Park HJ. Stability investigation of hyaluronic acid based nanoemulsion and its potential as transdermal carrier. Carbohydrate Polymers. 2011;83(3):1303-1310.

14 Ngan CL, Basri M, Tripathy M, Abedi Karjiban R, Abdul-Malek E. Physicochemical characterization and thermodynamic studies of nanoemulsion-based transdermal delivery system for fullerene. The Scientific World Journal. 2014;2014:219035.

15 Dolez P, Vinches L, Wilkinson K, Cloutier Y, Dion C, Truchon G, et al. Development of a method of measuring nanoparticle penetration through protective glove materials under conditions simulating workplace use. Quebec: IRSST; 2013.

16 Dupuy N, Duponchel L, Amram B, Huvenne JP, Legrand P. Quantitative analysis of latex in paper coatings by ATR-FTIR spectroscopy. Journal of Chemometrics. 1994;8(5):333-347.

17 Martins-Franchetti SM, Rodrigues MLBO, Pedro RJ, Campos A. Biodegradação de luvas de látex em solo. In: Anais do IX Congresso Brasileiro de Polímeros; 2007; Campina Grande. São Carlos: ABPol; 2007. p. 1-6 [acesso em 21 nov. 2017]. Disponível em: https://www.ipen.br/biblioteca/cd/cbpol/2007/PDF/20.pdf

18 Safety Office. Glove selection guidance. 4th ed. Cambridge: University of Cambridge; 2016. 42 p. [acesso em 18 out. 2017]. Disponível em: https://www.safety.admin.cam.ac.uk/files/hsd059c.pdf

19 Provincial Infectious Diseases Advisory Committee. Pidac: routine practices and additional precautions in all health care settings. Ontario: PIDAC; 2012.

20 Singh S. Refractive index measurement and its applications. Physica Scripta. 2002;65(2):167-180.

21 Galvão AC, Robazza WDS, Silva IR, Almeida CM. Estudo do índice de refração de soluções líquidas binárias formadas por álcool e água em diferentes temperaturas. Ciência e Natura. 2015;37(4):641-650.

22 Netz PA, Ortega GG. Fundamentos de físico-química: uma abordagem conceitual para as ciências farmacêuticas. Porto Alegre: Artmed; 2014. 296 p. 
23 Agência Nacional de Vigilância Sanitária. 5.2.16 Turbidimetria e nefelometria. $5^{\text {a }}$ edição: volume 1, Brasilia: Anvisa; 2010. Farmacopeia brasileira; p. 104. (vol. 5) [acesso em 6 set. 2017]. Disponível em: http://www.anvisa. gov.br/hotsite/cd_farmacopeia/pdf/volume\%201.pdf

24 Occupational Safety and Health Administration. Working safely with nanomaterials. Washington: OSHA; 2009.

25 Vogt A, Combadiere B, Hadam S, Stieler KM, Lademann J, Schaefer H, et al. $40 \mathrm{~nm}$ but not 750 or $1500 \mathrm{~nm}$, particles enter epidermal cdla + cells after transcutaneous application on human skin. The Journal of Investigative Dermatology. 2006;126(6):1316-1322.

Recebido em: 26 Jun. 2019

Aceito em: 15 Maio 2020 